Stefan Adam*, Gregorio Avilés, Domenico Ferrari, Jeremias Amstutz, Luca Crivelli, Cavedon Enrico, Anja Gafner, Spartaco Greppi, Daniela Schmitz, Bernadette Wüthrich and Daniel Zoebeli

\title{
Work Integration Social Enterprises in Switzerland
}

\author{
DOI 10.1515/npf-2016-0014
}

Abstract: The article aims to present the Swiss landscape of work integration social enterprises (WISEs). The origins of SEs are rooted within three distinct social security regimes, i. e. disability insurance, unemployment insurance and social assistance.

*Corresponding author: Stefan Adam, Institute Coaching, Counselling, Social Management, University of Applied Sciences and Arts Northwestern Switzerland, School of Social Work, Riggenbachstrasse 10, Olten 4600, Switzerland, E-mail: stefan.adam@fhnw.ch

Gregorio Avilés: E-mail: gregorio.aviles@supsi.ch, Domenico Ferrari:

E-mail: domenico.ferrari@supsi.ch, University of Applied Sciences of Southern Switzerland (SUPSI), Department of Business economics, Health and Social care, via Cantonale 16E, Manno 6928 Jeremias Amstutz, Institute Coaching, Counselling, Social Management, University of Applied Sciences and Arts Northwestern Switzerland, School of Social Work, Riggenbachstrasse 10, Olten 4600, Switzerland, E-mail: jeremias.amstutz@fhnw.ch

Luca Crivelli, University of Applied Sciences of Southern Switzerland (SUPSI), Department of Business economics, Health and Social care, via Cantonale 16E, Manno 6928,

E-mail: luca.crivelli@supsi.ch

Cavedon Enrico, Institute Coaching, Counselling, Social Management, University of Applied Sciences and Arts Northwestern Switzerland, School of Social Work, Riggenbachstrasse 10, Olten 4600, Switzerland, E-mail: enrico.cavedon@fhnw.ch

Anja Gafner: E-mail: anja.gafner@supsi.ch, Spartaco Greppi: E-mail: spartaco.greppi@supsi.ch, University of Applied Sciences of Southern Switzerland (SUPSI), Department of Business economics, Health and Social care, via Cantonale 16E, Manno 6928

Daniela Schmitz, Head of Research Area „Innovation \& Accounting/Auditing“, Institute for Management \& Innovation, Swiss Distance University of Applied Science, Althardstrasse 60, Regensdorf 8105, Switzerland, E-mail: daniela.schmitz@ffhs.ch

Bernadette Wüthrich, Institute Coaching, Counselling, Social Management, University of Applied Sciences and Arts Northwestern Switzerland, School of Social Work, Riggenbachstrasse 10, Olten 4600, Switzerland, E-mail: bernadette.wuethrich@fhnw.ch

Daniel Zoebeli, Head of Research Area „Innovation \& Accounting/Auditing“, Institute for Management \& Innovation, Swiss Distance University of Applied Science, Althardstrasse 60, Regensdorf 8105, Switzerland, E-mail: daniel.zoebeli@ffhs.ch 
The debate around SE has a longer tradition in the French-speaking part of the country, while it seems more recent in the German-speaking area. The literature review presented in this article allowed for identifying at least five definitions of the WISE model emerging from Swiss civil society. The heterogeneity of their normative elements reflects different conceptions about the positioning of SE in the market, its resources mix, the integration goals and the wage models for the disadvantaged workers. This article draws on a recent empirical survey from which some keyfigures concerning the size of the WISE sector have been estimated. Descriptive statistics on legal forms, profit allocation, target-groups, integration goals, remuneration models, economic sectors and the competitive nature of WISEs are provided. By means of a cluster analysis, four models of SE have been identified. The article concludes with a discussion of some of the major issues around the future development of the sector.

Keywords: WISE, social entrepreneurship, work integration social enterprise, work integration, social enterprise

\section{Introduction}

In the Swiss context, the term "social enterprise" (SE) is usually associated with, and limited to, the field of work integration (Adam 2013). ${ }^{1}$ As in other countries, the Work Integration Social Enterprise (WISE) is currently the dominant and more visible model of SE. However, whereas the hybridization of business and institutions founded with the aim of integrating vulnerable persons into employment began in many European countries in the second half of the 1970s, in Switzerland it was slower in gaining momentum. This is probably due to the success of the country's economic and social model (Crivelli, Bracci, and Avilés 2012a). Nevertheless, since the 1990s, Switzerland has also been facing a significant increase in the number of people excluded from the labour market and the emergence of problems associated with the financial sustainability of the welfare state (Adam et al. 2016).

Therefore, in the last two decades the development of forms of WISE has been observed, mainly initiated by not-for-profit organizations responding to the needs of unemployed people (Crivelli, Bracci, and Avilés 2012a). ${ }^{2}$

1 Indeed, in this article we use "SE" and "WISE" (work integration social enterprise) in an interchangeable way. However, there is also a wider conception of SE which has recently been put forward in the German-speaking area of the country and refers to SEs delivering social services to poor families.

2 Prior to 1990 the emphasis was on people with disabilities. 
The "typical" institutional trajectory of SE consisted in what Defourny and Nyssens (2016) describe as a move of general interest organizations (hitherto relying mainly on non-market income, if not fully subsidized by public authorities) towards more market-oriented activities with the possible adoption of more business-like methods, resulting in the so-called entrepreneurial not-forprofit model of SE.

There currently are two umbrella organizations of SEs in Switzerland: the CRIEC - a specific committee of Insertion Suisse representing WISEs coming from the French-speaking part of the country - and FUGS representing WISEs of the German-speaking area. The presence of these groups of interest reflects a bottom-up movement aimed at the recognition of a SE sector in Switzerland. In fact, while many European countries have adopted specific laws for SEs or adapted their ordinary legislation (Fici 2015), in Switzerland there is currently neither specific legal forms nor specific legal frameworks and - generally - no support schemes especially conceived for SEs. ${ }^{3}$

Despite the lack of official recognition, there is a growing interest for SE by policy-makers, both at regional and national levels. This is due to the rise of long-term unemployment, the limited effectiveness of active labour market policies in fostering the work integration of the most disadvantaged people, and the increasing need to cut and "rationalize" public spending. In this context, the "WISE model" is expected to be a potentially innovating form of dealing with long term unemployment and social exclusion. ${ }^{4,5}$ However, the lack of a specific legal framework, the federalism and the multiplicity of widely differing models that have taken root in Switzerland's three principal language regions, have tended to reduce the visibility and the understanding of these institutions, and

3 To our knowledge, only a few Cantons have so far experimented pilot projects aimed at supporting the development of WISEs in the field of social assistance. For example, the Canton Valais recently introduced a public scheme which sustains WISEs during the start-up period. For a first evaluation of this experience, the reader can refer to Da Cunha, Buchs, and Rivola (2014).

4 Two examples witness the growing interest for SE in the public sphere at the national level: (a) SE was described as an important «tool» for the poverty reduction by the Federal Council in the «National Action Plan against Poverty» of 2010 (Cantons were explicitly invited to take concrete actions for the development of this sector); (b) the adoption of the "Carobbio Postulate”, a parliamentary act of 2013, that asked the Federal Council to collect detailed empirical data on SEs.

5 However, in the public debate there is no lack of critiques towards the SE model. In particular, the detractors consider SE to be a workfare instrument used to activate welfare recipients in a coercive way, as well as a risk of wage dumping or unfair competition for forprofit enterprises. 
they also have represented a serious challenge for their empirical identification (Crivelli, Bracci, and Avilés 2012a). ${ }^{6}$

The aims of the article are four-fold.

Firstly, to sketch the historical development of the Swiss welfare state and its impact on the emergence of specific models of SE (Section 1).

Secondly, to identify the main concepts of SE proposed by civil society's actors, and to compare them with the definitional criteria of the EMES ideal-type (Section 2).

Thirdly, to summarize the scientific knowledge produced so far on the topic, without the ambition of being exhaustive (Section 3).

Fourthly, to present a recent empirical survey that tried to estimate the number of WISEs in Switzerland, the size of the sector, to describe the main characteristics of these organizations and to identify the different existing models of SE (Sections 4 and 5).

Finally, Section 6 provides some concluding remarks about future challenges for the sector.

\section{The Historical Origins of SEs}

This section focuses on some relevant principles and cornerstones of the Swiss welfare state development and their impact on the emergence and the multitiered structure of the work integration field. ${ }^{7}$

Before the Second World War, poverty was often regarded as self-inflicted and as a sign of weakness of character. A poor person who was considered able to work was stigmatized and ostracized. Structural causes of poverty were not taken into account. This phenomenon illustrates an important social policy principle which has retained its validity until the present in debates on work integration: the individual's responsibility to avoid poverty by means of paid work.

\footnotetext{
6 As regards policy-makers, the understandings of SE are quite heterogeneous. One usually recognizes that SE combines a social mission and an economic project, but there is rarely a clear and detailed conception of the SE model and its specific features. In fact, there is often no clear distinction between WISEs and other similar organizations, such as the sheltered workshops for the disabled and the secondary labour market programs (i.e. "traditional" not-for-profit organizations offering temporary placements for unemployed people).

7 Most elements included in this section are based on the historical report on social security in Switzerland (BSV 2014).
} 
Another important feature of the Swiss political system is vertical subsidiarity: municipalities are the first level of authorities to find solutions for social problems. If problems cannot be handled on the local level, they are managed by the Cantons and the Federal Government. This principle explains why most of the work integration measures for welfare recipients were (and many still are) financed by municipal administrations. Contrary to social insurance schemes controlled at the federal level, Cantons and municipalities have kept substantial powers in the social assistance field (Bertozzi, Bonoli, and Ross 2008). ${ }^{8}$ Following the principle of horizontal subsidiarity, the private sector also historically played an important role in the provision of social security.

Up until the Second World War, the Swiss welfare state remained weak and fragmented. With the introduction of the federal old age insurance scheme in 1948, a tentative development towards a stronger welfare state was initiated. However, in comparison with other countries, the development was gradual and low-key. In the late 1950s, the federal law on invalidity (or disability) insurance (IVG) was introduced. Consequently, sheltered workshops for disabled people, mainly promoted by not-for-profit organizations, were recognized and financed through federal and cantonal funds. ${ }^{9}$ The law does not obligate companies to employ "quotas" of disabled individuals. At this time, the Federal Government was convinced that the persistent shortage of labor would create sufficient incentives for companies to hire people with disabilities without setting any legal constraint. However, this was not the case and the number of sheltered workshops increased. In addition, the several years of economic recession experienced by Switzerland during the 1970s were an obstacle to the integration of people with intellectual, mental and physical disabilities in the regular labour market.

In contrast with most European countries, Switzerland had no compulsory unemployment insurance until the 1970s; the federal law on mandatory unemployment insurance (AVIG) was adopted in 1982. Since that time, access to the labour market has become more difficult for low-qualified individuals. Indeed, the economy has increasingly been focusing on qualified workers. For this reason, work and social integration projects, stemming from the initiative of municipalities and not-for-profit organizations, started to provide occupations for the low-qualified and long-term unemployed, as well as marginalized

8 Nowadays, the room for manoeuvre within the municipalities is especially large in the German-speaking part of the country.

9 Since 2008, the Cantons are responsible for the regulation and financing of the sheltered workshops (collective projects), while the Swiss Confederation has kept the responsibility for individual work integration programs only. 
people. The first initiatives were launched during the 1980s and were targeted at drug addicts. At the same time, temporary employment and training programs were introduced for the youngest welfare recipients (Lindenmeyer and Walker 2010).

These initiatives multiplied and were extended to other target groups during the 1990s, when Switzerland faced a strong increase in the unemployment rate and increasing financial problems for social insurance and social assistance schemes. ${ }^{10}$ The unemployment insurance, as well as other social security schemes, were thus revised according to activation principles (Bertozzi, Bonoli, and Ross 2008) and the Federal Government began to promote "active programs" in order to reintegrate the unemployment insurance beneficiaries in the ordinary labour market as quickly as possible. An important activation scheme for the hard-to-place unemployed is the so-called Temporary Employment Programs, organized in the public and non-profit sectors. The field of social assistance, the Cantons and the biggest municipalities developed a wide range of programs including temporary employment - with heterogeneous designations and different underlying concepts (Pfister 2009). As for other activation measures, participation in temporary employment has generally a binding nature, since noncompliance implies the risk of incurring benefit sanctions.

In this complex institutional context, several experiences of social entrepreneurship, mainly launched by general interest organizations, have seen the light in order to respond in an innovative way to the rising exclusion. Contrary to classical non-profit work integration organizations (WIOs), the SE model is characterized by a stronger market orientation, a higher economic risk and the will to provide disadvantaged workers with a real work experience (i. e. a "job" as close as possible to the regular labour market).

The administrative category of the beneficiaries and the different sources of public funding have largely determined the emergence and the organization of WISEs, giving rise to multiple SE models. In the French-speaking part of the country, Dunand (2012) identified three historical families of WISEs:

- The entreprises d'emploi adapté for the work integration of disability insurance pensioners.

- The entreprises sociales d'insertion, that have developed since the 1980s with the aim of integrating social assistance recipients.

- The temporary employment programs SE model, addressing the needs of unemployment insurance beneficiaries.

10 The "administrative" unemployment rate, based on the number of unemployed registered at the Public Employment Service, rose from $0.5 \%$ in 1990 to $1.9 \%$ in 1991 and 3.8\% in 1993 (Bertozzi, Bonoli, and Ross 2008). 
In the German-speaking area, the debate on SE seems to be more recent, since its origin can be traced back to early 2000s. In this region the discussions on SE are based on the idea that a part of the workforce (particularly social assistance recipients and people with severe health impairments) is permanently excluded from conventional work (Kehrli 2007). While in the French-speaking area the dominant goal of SEs is to make a bridge to ordinary labour market or vocational training, the "German strategy" aims at creating a complementary market, avoiding a competition with for-profit enterprises.

\section{Understanding the Concepts of SE: A Large Spectrum of Definitions}

Because it is likely - as many other countries did - that public bodies will recognize and regulate the sector of SEs to some extent in the near future, it is interesting to analyze the heterogeneous definitions coming from civil society's actors. In the following list the most relevant normative concepts proposed by field practitioners are briefly outlined:

- Dunand and Du Pasquier (2006) identified four definitional criteria for the entreprises sociales d'insertion situated in the French-speaking area of Switzerland. These WISEs generally aim at the reintegration of disadvantaged workers in the ordinary labour market.

- VPOD is the Switzerland's public service trade union. This organization proposed in 2007 the concept of Integration firm (Integrationsfirma). Contrary to other concepts, this definition suggests that work integration is primarily the responsibility of the State and not of private actors (VPOD 2007).

- The definition of Social Firm given by Social Firms Europe (CEFEC) became a reference for many practitioners in the German-speaking area of the country. ${ }^{11}$ Most of them offer employment to workers with disabilities in sheltered workshops funded by permanent public subsidies.

- FUGS is the Association of entrepreneurially-managed Social Firms. This umbrella organization, founded in 2013, covers the German-speaking part of the country and suggested its own definition of social firm (Sozialfirma),

11 The CEFEC definition of Social Firm can be found on the following website: http://socialfirmseurope.org. 
derived from the experience of SEs offering a job for long-term unemployed people with severe social problems and/or physical and mental disabilities. Here the focus is placed on criteria and management tools which are typical of private enterprises. ${ }^{12}$

- Following the Second national conference on WISEs, which took place in 2012, a sort of "least common denominator" of the different models was defined by practitioners, known as the "Consensus of Sierre" (Dunand and Rey 2013). According to this definition, SEs are private organizations, taking risks on the market and aiming at the integration of disadvantaged workers. $^{13}$

The abovementioned concepts reflect the multiple existing models of work integration organizations and the specificities of different language regions. Table 1 illustrates and compares their normative criteria using the well-known EMES ideal-type of SE as a compass (Defourny and Nyssens 2012). The latter identifies three distinct dimensions of SE and nine indicators: (a) three indicators of the economic dimension, i. e. a continuous activity producing and selling goods and/ or services, a significant level of economic risk and a minimum amount of paid work; (b) three indicators reflecting the social mission, i. e. an explicit aim to benefit the community, an initiative launched by a group of citizens and a limited profit distribution; (c) three indicators of a specific model of governance, i. e. a high degree of autonomy, a decision-making power not based on capital ownership and a participatory nature involving various stakeholders.

Concerning the economic dimension, it is interesting to note that the definitions given by FUGS and VPOD confine SEs to act in non-competitive markets, i. e. markets without private for profit or public competitors. The SE should thus be positioned in a sort of "residual" or "complementary" market. We also observe a difference with regard to the level of wage a WISE should pay to its disadvantaged workers. In the Integrationsfirma, this reaches the level of a market minimum wage, whereas in the Sozialfirma the wage is adjusted to the performance of the employee (Wüthrich et al. 2012). The Social firm model pays either a market wage or a wage appropriate to the work. Finally, the CEFEC Social

12 The FUGS definition of Sozialfirma can be found on the following website: http://www.sozialfirmen.ch.

13 Acknowledging the difficulty of defining a single Swiss model, the umbrella organizations also identified eight elements of differentiation between the heterogeneous types of WISEs: the target group (one single group or mixed groups), the nature of the market (competitive, mixed or non-competitive), the intensity of the integration services provided, the time horizon of the integration in SE, the degree of market orientation, the degree of market exposure, the importance of the wage paid to disadvantaged employees and the institutional autonomy. 


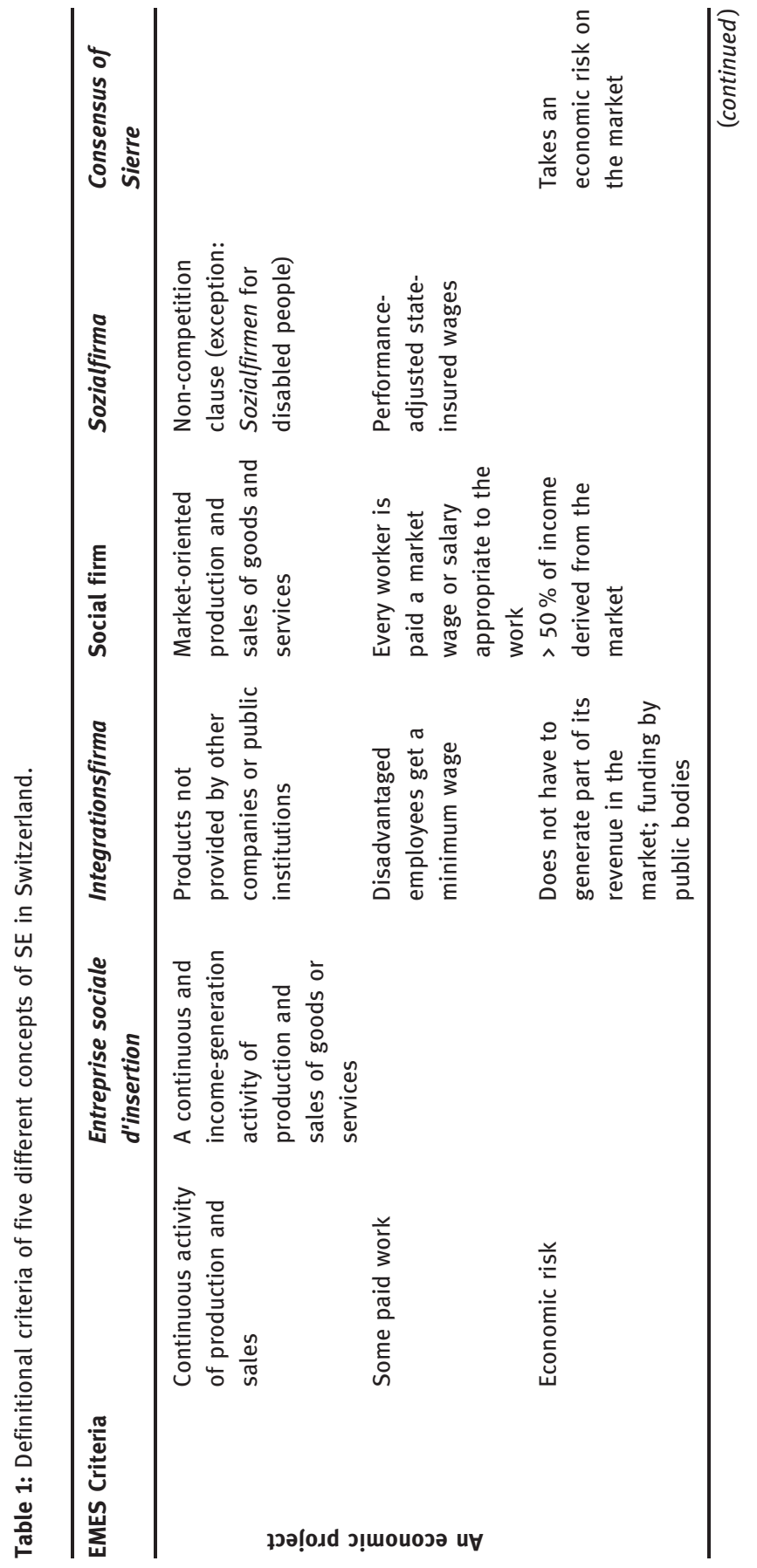




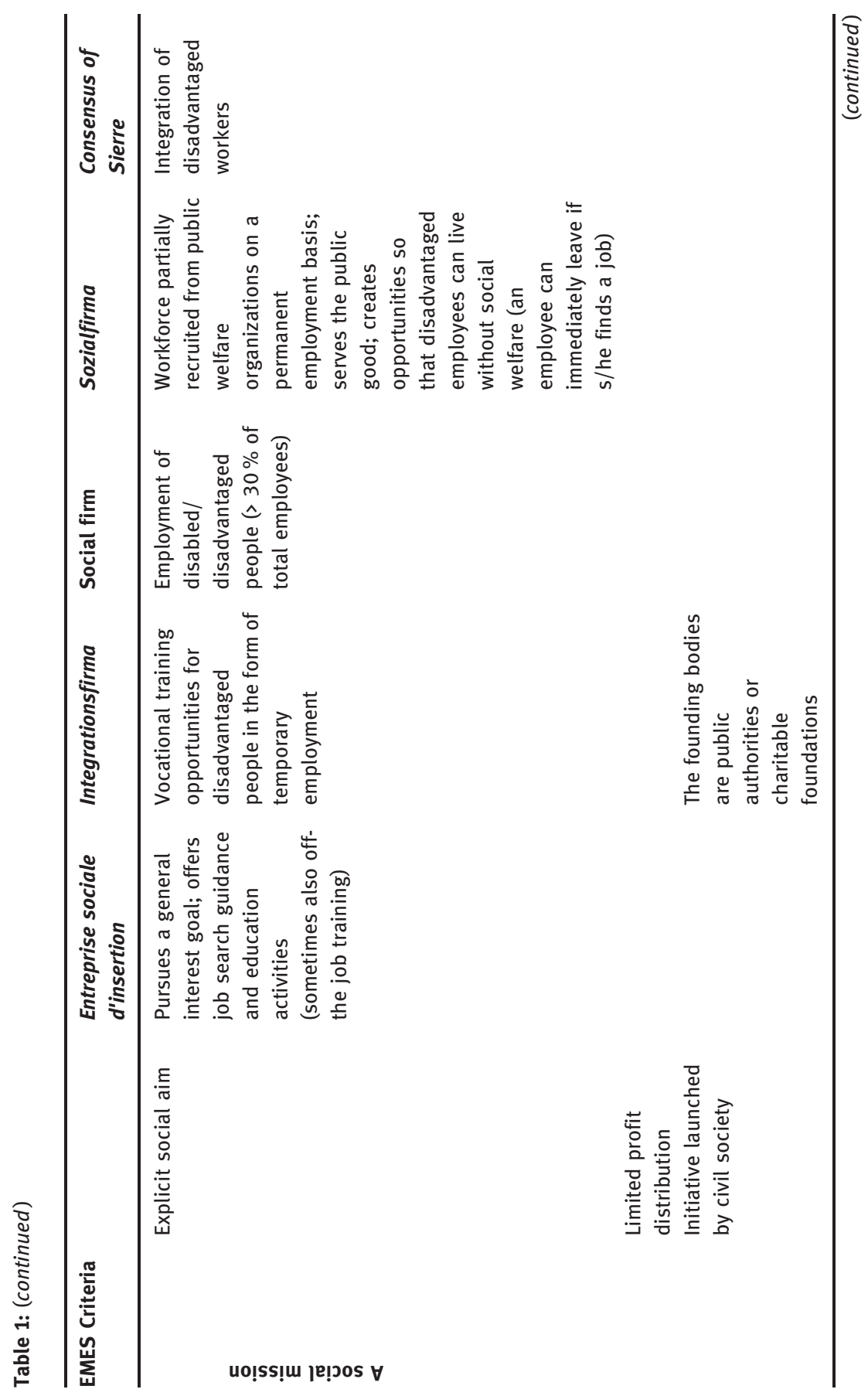




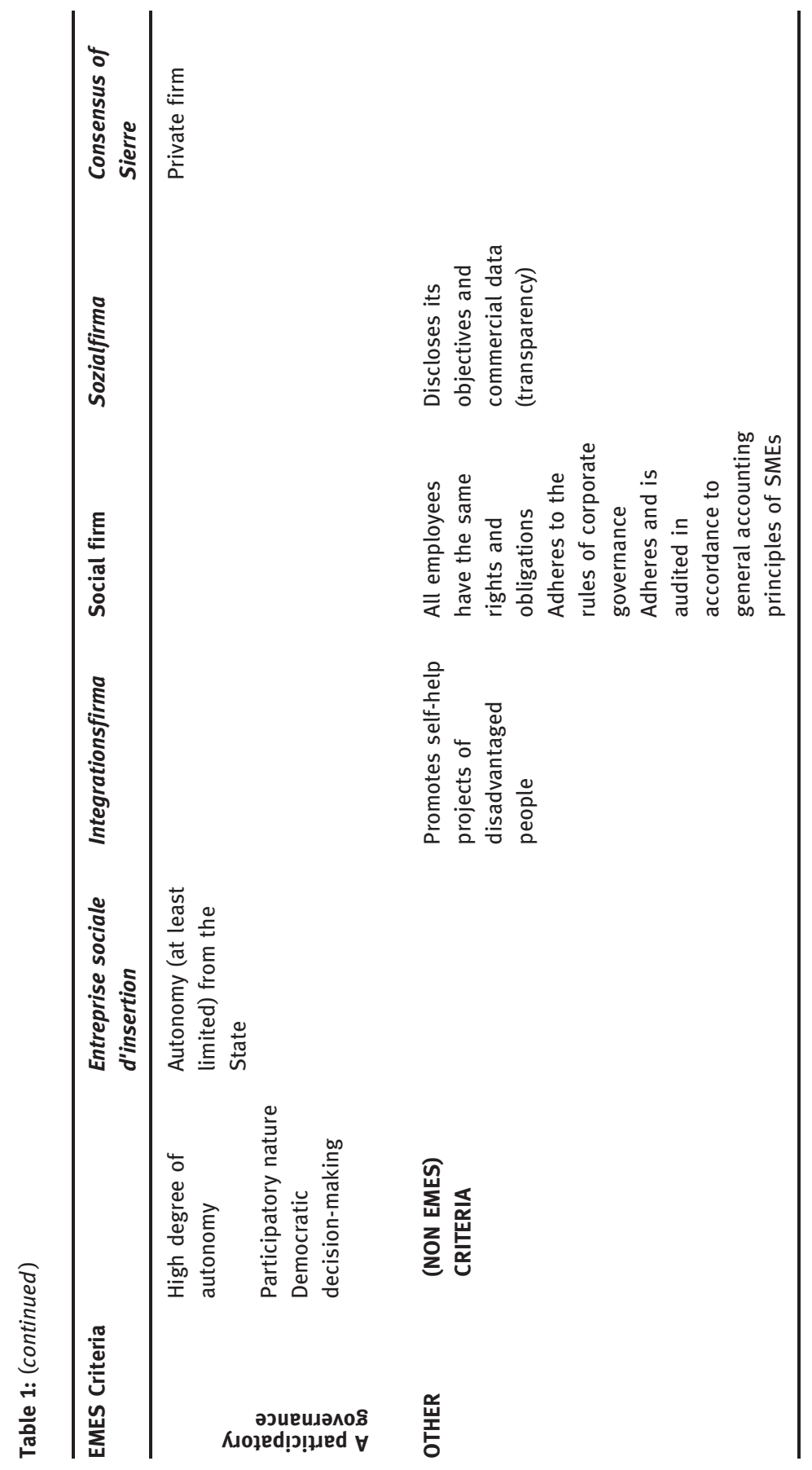


Firm concept and the Consensus of Sierre stress the importance of taking risks on the market (the former indicate an arbitrary threshold of $50 \%$ of market income for the sake of distinguishing WISEs from traditional NPOs). On the contrary, the funding of the Integrationsfirma should be ensured by public bodies.

As regards the social aim, while the common trait of WISEs is the offer of employment and formative opportunities for disadvantaged workers, the modes and goals of integration are different. In the Sozialfirma the working experience should take the form of permanent work contracts. On the contrary, the Entreprise sociale d'insertion and the Integrationsfirma should offer temporary training opportunities with the aim of a rapid reintegration in the ordinary labour market. In the former model that goal is pursued also through job search guidance. Concerning the two other EMES indicators of the social dimension, i. e. a limited profit distribution and an initiative launched by civil society, the concepts under review rarely include any explicit element. VPOD is the only actor that makes a statement regarding the founders of an Integrationsfirma: in fact, the initiative should come from general interest organizations, i. e. public bodies or charitable foundations.

With regard to the governance sphere, the Entreprise sociale d'insertion should be at least partially autonomous from the State. Following the concept proposed by the "Consensus of Sierre", a SE should assume - in addition to a high degree of economic risk - a private legal form. Both elements are likely to assure at least a certain degree of autonomy from public bodies. On the other hand, since it can rely on public funds only, the Integrationsfirma model does not imply being autonomous from the State.

Perhaps the most striking remark concerns the lack of elements related to the participatory nature and the democratic decision-making. This does not mean, of course, that a democratic governance is absent in the practice, but practitioners do not accord a particular and explicit importance to that dimension in their definitions. This has been confirmed by Crivelli, Bracci, and Avilés (2012a), who measured the organizations' degree of awareness of what a social enterprise is. Among the EMES criteria, the one the interviewees considered most important in identifying a SE was its pursuit of a social objective, while the participatory and democratic element was the least important.

\section{State of the Art of the Scientific Knowledge}

Since mid-2000, a few scientific contributions have been published on SE in Switzerland, denoting the birth of an interest for this topic in the academic 
sphere, and particularly within the universities of applied sciences. ${ }^{14}$ In the following lines, because of space limits, we only present three empirical studies that have been completed at regional and national level.

To our knowledge, the study of Tattini and Bruttin (2006) was the first scientific research on SE in Switzerland. It adopted a qualitative approach and focused on a sample of 12 WISEs mainly operating in the French-speaking part of the country. The authors proposed a definition of WISE based on the EMES criteria but adapted to the Swiss context. They excluded some EMES elements, since they are difficult to measure or not much relevant for the specific context, i. e. a high degree of autonomy, an initiative launched by a group of citizens, a decision-making power not based on capital ownership and a participatory nature involving various stakeholders. ${ }^{15}$ Moreover, the definition includes two additional criteria: the existence of an employment contract for the disadvantaged workers - that should be as similar as possible to a regular contract - and the offer of supervision and psycho-social assistance, that can be assured either by "technical" staff (this usually is the case for the more entrepreneurial WISEs) or by social workers.

Tattini and Bruttin proposed to classify WISEs according to two axes:

a) The integration goal of the beneficiaries. On the one hand, the WISEs that occupy unemployment insurance beneficiaries and social assistance recipients generally offer a temporary experience with the goal of reintegration into the regular labour market. On the other hand, WISEs for the disabled tend to offer long-term employment contracts.

b) The logic underlying the production of goods and services. One can distinguish the SEs whose activities are mainly linked to public schemes and to their financing, from the SEs which adopt a more market-oriented logic. The latter have a higher degree of autonomy from the State, but this in turn implies a higher demand in terms of productivity.

14 Apart from the scientific studies, a number of bachelor and master thesis, as well as articles and books for dissemination purposes have seen the light (among others: Dunand and Du Pasquier 2006; Amgarten and Widmer, 2007; Kehrli 2007; Adam 2008; Adam 2012; Darioli 2013). A broad overview of various types of SEs in Switzerland - also beyond work integration - is contained in Gonin and Gachet (2015).

15 The authors underline that the participation of the disadvantaged workers in the decisionmaking process is very limited, although the participation in the daily routine is usually important. This aspect follows the practice of European WISEs (Campi, Defourny, and Grégoire 2006; Hulgard and Spear 2006), where the temporary nature of work integration projects and the social difficulties of the individuals concerned do not (often) allow the effective involvement of disadvantaged workers. 
The qualitative study by De Jonckheere, Mezzena, and Molnarfi (2008)) is restricted to six WISEs coming from the French-speaking area of Switzerland. The authors analyzed, through the perceptions of the main stakeholders, the impact made by a working period in a SE on the skills and the capabilities of the beneficiaries. The WISE's staff essentially cultivates the social, personal and "para-professional" skills (such as regaining the rhythms of work and following the productive constraints of a firm), considered to be necessary prerequisites for work reintegration. Nevertheless, in a period of bad economic conjuncture with limited hiring opportunities, the economic activity aims especially at maintaining social contacts, reinforcing social recognition and furthering personal development. ${ }^{16}$ The research also points to a few paradoxes underlying the WISE's functioning. These are linked to the tensions between the revenue-generating constraints, the non-competition restriction and the political pressures towards the aim of reintegration in the regular labour market, on the one hand, and the social goals related to the multiple needs of the beneficiaries on the other hand.

The first exploratory and quantitative study on WISEs at the national level was conducted by Crivelli, Bracci, and Avilés (2012a, 2012b). The researchers considered organizations affiliated to the principal umbrella organizations, those mentioned in past publications and entities that defined themselves as SE or WISE. Forty-eight organizations participated in the survey. As regards the social nature, the contribution of most WISEs is not limited to offering disadvantaged people the opportunity to access the labour market, but they provide their beneficiaries and/or the local area with a wide range of social, training and environmental services. They also provide housing and leisure services (mainly in the case of organizations working with the disabled), training and retraining courses (mainly for the unemployed), as well as consultancy and job-search services. Their social nature is also expressed in the provision of social support for the disadvantaged employees.

With an average self-financing rate of $40 \%$, the degree of financial risk assumed by WISEs was judged as rather modest (in 12 cases only market-based resources exceeded $50 \%$ of total income). ${ }^{17}$ This rather limited level of economic risk stems from the predominance of public subsidies in the organizations'

16 However, the hybrid nature of the organizations does not allow the beneficiaries to be recognized as "real" workers (De Jonckheere, Mezzena, and Molnarfi 2008).

17 Nevertheless, this modest result is in part due to the presence in the sample of some "social institutions", with very little market orientation. Moreover, a partial subsidy of the WISEs' commercial products or services could be justified, given the collective goods it generates (e. g. environment protection, social inclusion, fostering of the beneficiaries well-being and quality of life). 
resource mix. Whereas public subsidies (direct and indirect) ${ }^{18}$ paid to WISEs are on average higher than in other European countries, the mix of public-private financing is similar in both contexts. The substantial difference between Switzerland and the rest of Europe is thus not so much a matter of the way in which public contributions are made: in other European countries, SEs also channel public resources through sales to the State, while in Switzerland a straightforward subsidy system prevails. Another significant feature, which has obvious implications for productivity, lies in the high proportion of workers with disadvantages to those without, a personnel structure that is typical of the "sheltered" and the "secondary" labour markets. ${ }^{19}$

Finally, concerning the governance dimension, the decision-making processes are predominantly based on the "one member one vote" rule. A significant number of WISEs adopt a multi-stakeholder structure. The most influential stakeholders are private individuals external to the organization (in general experts), public bodies and NPO representatives. As compared with Europe (Campi, Defourny, and Grégoire 2006), in Switzerland there is a higher proportion of external individuals, while disadvantaged workers, staff and private sector agencies are under-represented and there is an almost complete absence of volunteers and customers.

The following sections are devoted to the presentation of a recent empirical survey that tried to estimate the number of WISEs in Switzerland and the size of the sector, to describe the main characteristics of these organizations and to identify the different models of SE. ${ }^{20}$

\section{Methodology of the Empirical Investigation}

The absence of a specific legal form and of a nation-wide register of WISEs is an obstacle to the identification of the field. A simple approach would have been

18 To assess the resources mix, in addition to direct public subsidies, the indirect wage subsidies should be taken into account. In fact, most SEs do save money on salary costs, because their disadvantaged workers benefit from significant social security allowances.

19 While this element justifies the getting of important subsidies, it could also be an issue for the social integration purpose, since the prevalence of disadvantaged employees can reinforce the social stigma.

20 The study consists of a nationwide research project titled "Social firms as the cornerstone of social innovation in Switzerland: general conditions, factors of success, and impact" (original title: Die Sozialfirma als Grundstein sozialer Innovation in der Schweiz: Rahmenbedingungen, Erfolgfaktoren und Wirkungen; abbreviation: INSOCH), funded by the Gebert Rüf Foundation. 
to focus only on SEs affiliated to umbrella organizations. However, this would have entailed the risk of excluding a large number of organizations that do not belong to an umbrella organization but can nevertheless be considered as WISEs. Therefore, it has been decided to develop a more comprehensive twostep approach, based on the fact that WISEs can be conceived as a sub-group of all Work Integration Organizations (WIOs), i. e. a vast field of entities (including for-profit, not-for-profit and public organizations), whose primary mission is the work and/or the social integration of unemployed and disabled people through a wide range of services and forms of support (e. g. training, job search guidance and coaching, psycho-social support, temporary or long term work experiences). This approach required a comprehensive collection of addresses from different sources: Federal Social Insurance Office, Cantonal Invalidity Offices, Cantonal Labour Offices, Cantonal Social Assistance Offices and umbrella organizations for WIOs and WISEs. On this basis, a total number of 1,159 WIOs were identified.

Data collection was performed by means of a computer-assisted web interview procedure; data referred to the year 2012. 700 of the 1,159 organizations completely filled in the questionnaire: a return rate of $60.4 \%$. Among the respondents sample, 313 Work Integration Social Enterprises (WISEs) were identified by applying two general criteria: (a) the offer of workplaces for disadvantaged people; (b) the achievement of sales revenues on the market. This meets a quite broad and "low-threshold" definition of SE. ${ }^{21}$ The rationale behind this choice was not to lose the richness and the heterogeneity of the different experiences observed in the field.

Drawing on the sampling data, we firstly attempted to extrapolate an estimate of the total value of some key variables in Switzerland, i. e. the number of WISEs, the number of beneficiaries involved in activities of production and sale of goods and/or services, the number of non-disadvantaged employees and sales turnover. The inferential approach is also based on a set of distinct assumptions concerning the potential existence of a selection bias, since WISEs could have been more motivated than WIOs to participate in the survey.

In a second stage, a set of descriptive analysis on a wide range of characteristics was performed, drawing on data coming from the WISEs' sample $(n=313)$. In this article, we will focus our attention on the following topics:

21 Indeed, the WISE sub-sample also includes organizations mainly offering workplaces with occupational purpose (see note 27) and gaining a very little amount of market income. Nevertheless, the cluster analysis (see Sections 5.3) allows to distinguish between different models of SE. 
legal forms and profit allocation, target groups, goals of work integration, wage models, economic sectors and non-competition clause. ${ }^{22}$

Finally, a two-step cluster analysis was conducted in order to identify a limited number of clusters. To this end, 16 variables were taken into account. To avoid a bias of the matching process by giving more importance to the one or the other variable, the optimal number of clusters was automatically decided by the software by applying the Bayesian information criterion of Schwarz. This procedure identified the existence of four main models of WISEs.

\section{Results}

In this section, we present the main results of the statistical analyses.

\subsection{Estimates of the Total Size of the Sector}

The starting point, for estimating the total number of WISEs operating in Switzerland, was the following three variables, which could be recorded for every organization belonging to the population $(n=1,159)$ : legal form, Canton and membership in chosen umbrella organizations.

Assuming the hypothesis that WISEs and non-WISE WIOs participated in the survey with the same probability, the global number of Swiss WISEs can be estimated in a range between 495 and 521 (depending on the variable on which the global estimation is based on, the results are slightly different).

According to the WISEs' sample, the number of beneficiaries who are concerned with production and sales activities is on average 104 people per WISE or 32,400 beneficiaries for all the 313 WISEs identified. The range for the global estimation of the number of beneficiaries is between 51,243 and 53,934. Using the same approach, the average number of regular employees of Swiss WISEs can be estimated. There is an average of 25 employees across 313 WISEs sampled (when converted into full-time units), that is a total number of 7,700 full-time equivalents. Taking this data as a reference, the range of the number of regular employees is between 12,169 and 12,807 full-time equivalents.

If one assumes the existence of a selection bias, one need to move to a more conservative inferential approach. The estimates have therefore been adjusted on the assumption that between 25 and 50 percent less WISEs are contained

22 More detailed results are available in Ferrari et al. (2016). 
among the 459 organizations which either didn't participate in the survey at all (309) or did not complete the questionnaire (150). Using this prudent approach, the number of WISEs would fall between 404 and 469, the number of beneficiaries between 41,821 and 48,551 and the number of FTE regular employees between 9,934 and 11,530. With the same method we estimated the global annual amount of market sales turnover generated by Swiss WISEs. This amount is substantial and covers a range between 618 and 797 million Swiss Francs depending on the supposed degree of selection bias.

\subsection{Descriptive Statistics on the WISE Sample}

\subsubsection{Legal Forms and Surplus Allocation}

Figure 1 shows the distribution of WISEs according to their legal forms. The latter have been divided into three groups. The group called "traditional not-for-profit and social \& solidarity economy organizations” includes foundations, associations and cooperatives. Corporations, limited liability companies, general partnerships and sole proprietorships have been assigned to the “companies” group. Finally, public administrators and autonomous public law bodies constitute the "public sector" group.

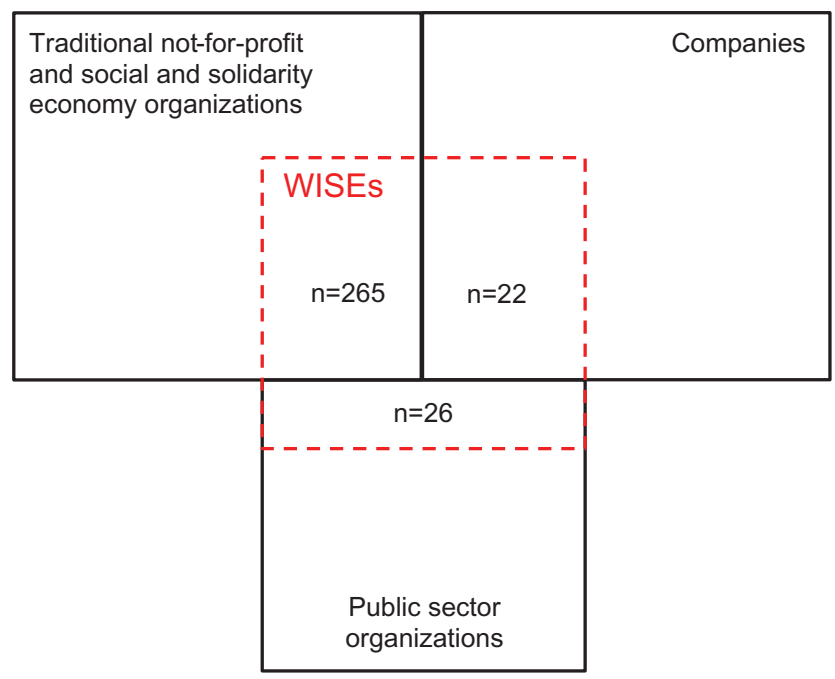

Figure 1: Legal forms of WISEs. 
The vast majority of WISEs belong to the first above-mentioned category and mostly adopt the legal form of an association or a foundation ( $80 \%$ of the sample). Contrary to other European countries, the social cooperative model is rarely present (only 5\%). The same applies to "companies"23 and "public sector" legal forms.

In almost $90 \%$ of the organizations legal form, internal statutes or tax exemption reasons explain the existence of a ban on profit distribution (this also applies to the majority of "companies"). On the other hand, in around $10 \%$ of WISEs a partial or full distribution of profits to shareholders or members is allowed.

Figure 2 describes the financial relationship between WISEs and their public funding bodies for the 289 organizations that have to comply with a partial or full dividend distribution ban. Nearly a quarter of these WISEs have to refund all the surplus to the funding bodies and can therefore be considered as zero-profit organizations; another $40 \%$ are required to refund a limited part of the surplus, whereas the remaining organizations - representing $47 \%$ of companies, $35 \%$ of not-for-profit entities and $30 \%$ of public sector SEs - can freely dispose of any surplus. Traditional not-for-profit and social \& solidarity economy
\[ (\mathrm{n}=249) \]

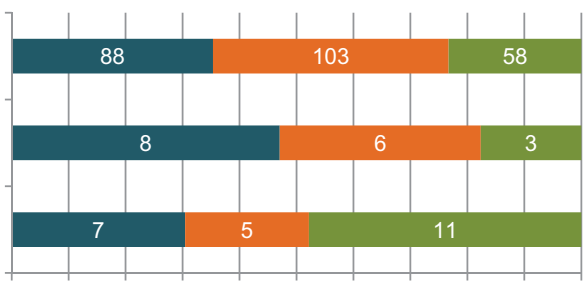

0\% $10 \% 20 \% 30 \% 40 \% 50 \% 60 \% 70 \% 80 \% 90 \% 100 \%$

- Any surplus is full available to the organization

- Part of any possible surplus must be refunded to funding bodies

- All surplus must be refunded to funding bodies

Figure 2: WISEs by surplus allocation and legal form.

\subsubsection{Administrative Categories of the Target Group}

Figure 3 illustrates the number of beneficiaries working in production and sales activities according to the WISE's target group(s). Altogether there are

23 With regards to firms, it is not rare the case, mainly in the German-speaking context, of notfor-profit entities which constitute and control independent companies (Crivelli, Bracci, and Avilés 2012b). Another possibility consists in not-for-profit organizations recovering existing forprofit businesses and transforming them into SE projects. 




Figure 3: WISEs by number and administrative category of beneficiaries.

74 organizations (24\%) which exclusively work with beneficiaries from the invalidity insurance ${ }^{24}$ and 49 organizations (16\%) providing job opportunities for social assistance recipients only. However, data show that most WISEs do not address a single target group, but instead a mix of beneficiaries and therefore receive financing from several public bodies. Among the 190 organizations with a mixed target group (61\%), 50 organizations employ both beneficiaries from the unemployment insurance and social assistance, 98 organizations incorporate beneficiaries from the invalidity insurance and social assistance regimes and 42 organizations include people from all three social security regimes simultaneously.

When focusing on single target-group organizations, one can interestingly observe that WISEs, which offer jobs to social assistance recipients, are rather small (i. e. in $80 \%$ of the cases, the number of beneficiaries lies between 1 and 50). On the contrary, around $30 \%$ of the WISEs which exclusively work with invalidity insurance beneficiaries are large organizations, each offering a workplace to more than 100 disadvantaged employees at any one time.

\subsubsection{Goal of Work Integration and Remuneration Models}

A central feature that helps to distinguish between different models of WISEs is the duration and the goal of the jobs offered to the beneficiaries (Davister, Defourny, and Grégoire 2003). Figure 4 clearly shows that the majority of WISEs only working with invalidity insurance beneficiaries mainly offers long-

24 This include both invalidity insurance pensioners and people following a reintegration program. 


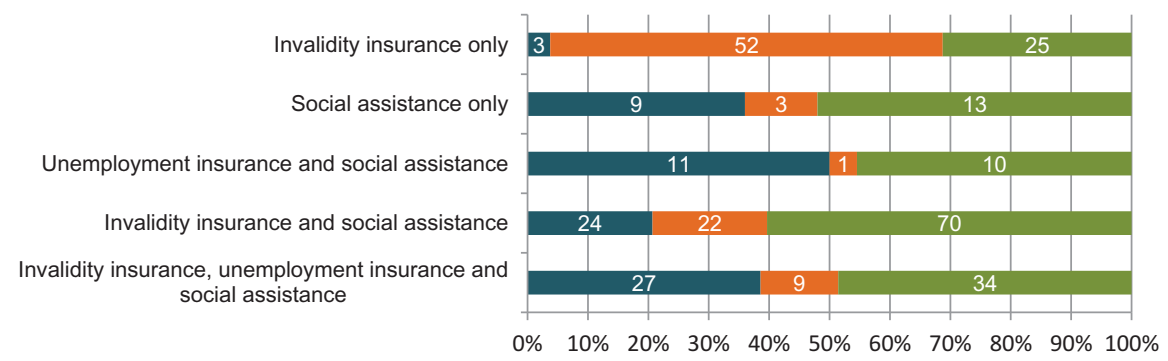

- The main objective is the provision of a short-term work experience for the purpose of rapid reintegration into the labor market

- The main objective is the provision of a long-term work experience in the organization

- Both objectives are important in our offer

Figure 4: WISEs by integration goal and target groups.

term jobs. On the contrary in WISEs which either exclusively host social assistance recipients, or both unemployment insurance beneficiaries and social assistance recipients, the aim of a rapid return to the mainstream labour market is clearly more dominant than the goal of long-term integration in the organization. However, as a consequence of the mixed target-groups, in almost $50 \%$ of WISEs both kinds of goals apply to a significant share of beneficiaries.

With regards to remuneration of the disadvantaged employees, there are four options. Figure 5 illustrates the main remuneration model adopted. Only 12 organizations ( $4 \%$ ) pay a market salary, but the beneficiaries of 86 organizations (about $27 \%$ ) are usually paid a salary equivalent to their limited productivity. In 115 organizations (about $37 \%$ of the sample) the beneficiaries receive a modest amount of money in addition to the pension or the daily allowance coming from social security. This model is dominant in SEs providing a long-term work experience. Finally, $32 \%$ of the organizations (100) pay no wages and their

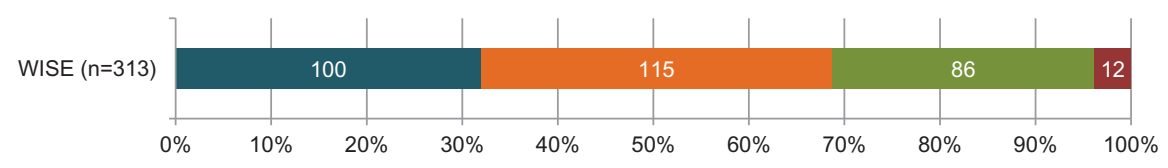

\footnotetext{
- No salary is paid to the beneficiaries by the organization

$\square$ A (modest) amount of money is paid to the beneficiaries in addition to their pension or daily allowance

$\square$ A salary which corresponds to the reduced productivity is paid to the beneficiaries

-A market salary is paid to the beneficiaries
}

Figure 5: WISEs by main remuneration model. 
employees continue to receive the usual social allowance. This is the prevailing model in WISEs offering a short-term work experience for the purpose of a rapid reintegration into mainstream labour market. In general, one can conclude that the wage models closest to a conventional work environment - i. e. $27 \%$ for salaries linked to productivity and only $4 \%$ for market salaries - are not widespread. When no regular contract is provided, nor a real wage is paid, the inclusion of the beneficiaries in the WISE is done through a public activation program; this is the usual condition of unemployed people and the most common for social assistance recipients.

\subsubsection{Economic Sectors and Non-Competition Clause}

Swiss WISEs act in a variety of economic sectors (see Figure 6). More than half of the WISEs are engaged in the processing of materials. Activities in the areas of "Installation, repairs \& maintenance" as well as "packaging \& shipping" are present in more than $40 \%$ of the organizations. Only $3 \%$ of WISEs have

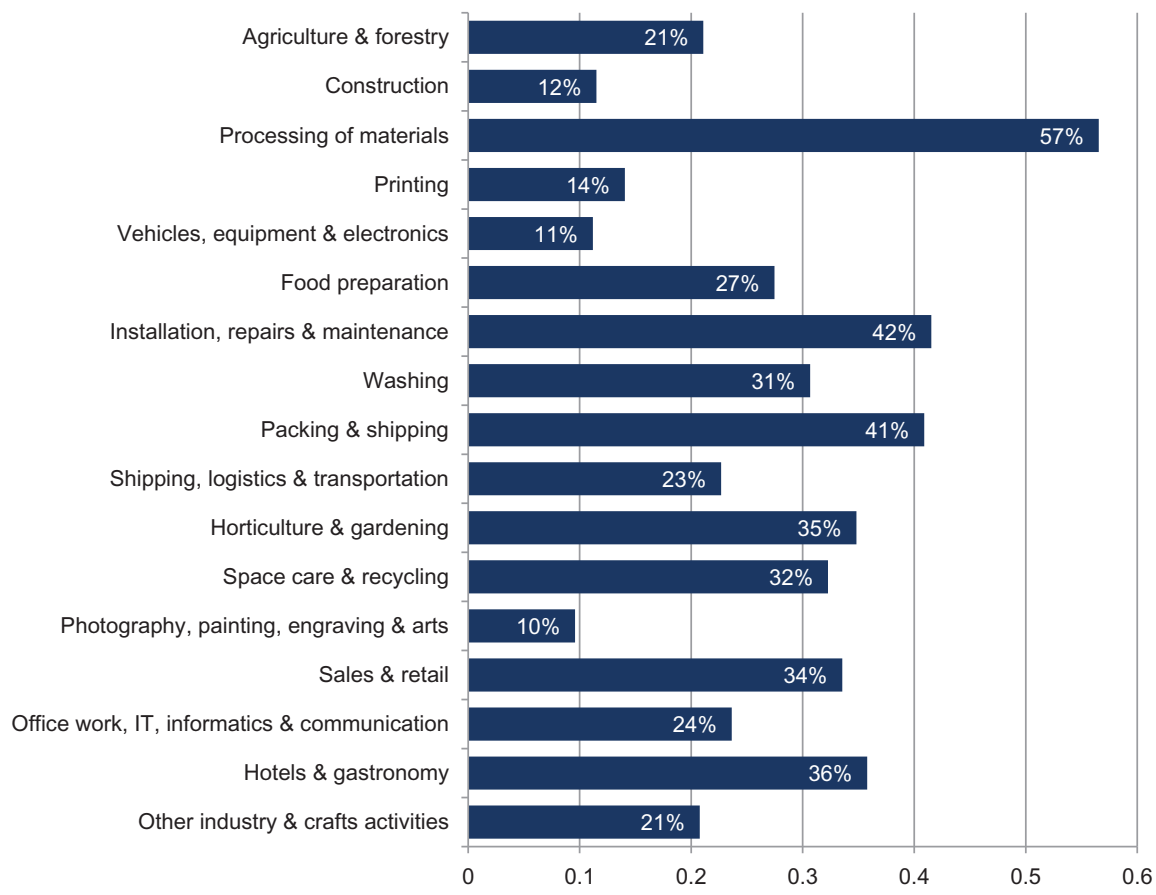

Figure 6: WISEs by economic sector. 
their main activity in the primary sector (agriculture), while $47 \%$ are engaged in the secondary sector (industry) and $50 \%$ active in the tertiary sector (services).

The competitive nature of the activity is another important variable that shape the relationships between SEs and the market. A complete or partial noncompetition clause often applies to WISEs. Behind the competition ban is the idea that public funding could allow WISEs to sell their products for belowmarket prices. The resulting distortion could make the economic situation of forprofit companies more difficult and ultimately increase the risk of job cuts. ${ }^{25}$ Figure 7 shows that a full or partial non-competition clause especially applies to WISEs employing unemployment insurance beneficiaries and/or social assistance recipients. On the other hand, a non-competition clause is rarely found in organizations employing beneficiaries from the invalidity insurance only or WISE's for both disabled people and social assistance recipients (around $5 \%$ of SEs in each case).

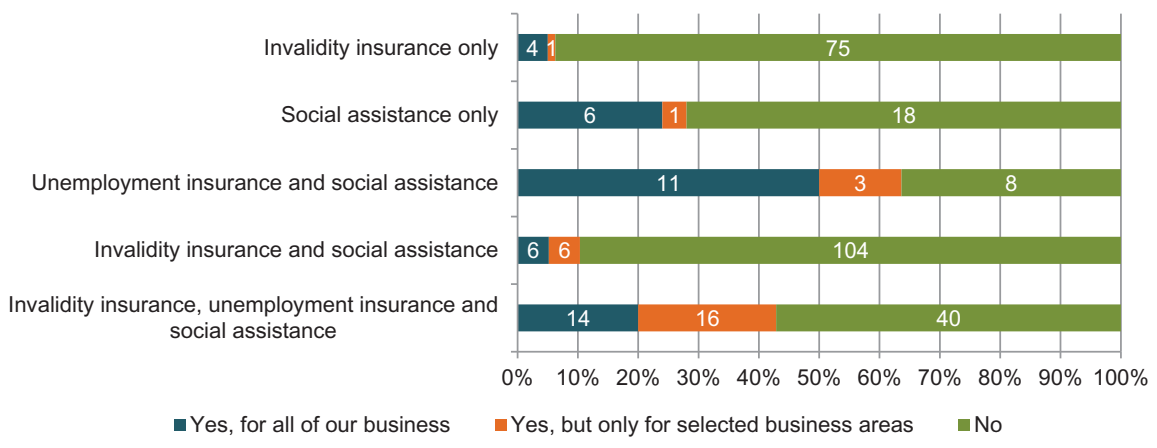

Figure 7: WISEs by non-competition clause and target groups.

WISEs that are active in "shipping, logistics \& transportation", "space care \& recycling” and "sales \& retail” are more likely to be limited by a full or a partial non-competition ban (the proportion lies around $30 \%$ ). In this regard, we should stress that many SEs belonging to the temporary employment program model for the unemployed are engaged in the recycling and retail of (second hand) electronic devices, furniture and clothes. This fact is likely to at least partially explain the results. ${ }^{26}$ Conversely, WISEs that are active in "printing",

25 However, the public debate generally ignores the potential macro-economic benefits derived from the WISE's economic activities (cfr. Marée 2005).

26 Indeed, the Unemployment Insurance Act includes an explicit competition ban towards forprofit companies for the Temporary Employment Programs (art. 64a AVIG). 
“food preparation”, “packing \& shipping” and "horticulture \& gardening” are less likely to be bounded by a non-competition clause (around $10 \%$ ).

\subsection{Cluster Analysis}

Four typical portraits of WISEs have been identified on the basis of the cluster analysis. The most influential variables in the clustering process were the following: the target group(s), the legal form (not-for-profit and for-profit in particular), the offer of accommodation and leisure activities, and the year of foundation. The main features of each cluster are briefly presented here.

\subsubsection{Cluster 1}

The 60 organizations belonging to Cluster 1 are focused on the target group of invalidity insurance beneficiaries. They adopt a traditional not-for-profit legal form and were established before 1990. This cluster is basically composed of large organizations with average operational costs of approximately 10 million Swiss Francs (SFr) and an annual average number of 83 beneficiaries. The market sales turnover is modest and approximately amounts to 975,000 SFr. Moreover, market sales represent the main source of funding for only $1.7 \%$ of the organizations in this cluster. The services provided to beneficiaries mainly are of residential and recreational nature (95\% of organizations) and workplaces pursue either an occupational purpose ${ }^{27}$ (93\% of organizations) or a production and sales purpose ${ }^{28}$ (60\% of organizations). In this group, traditional sheltered workshops are strongly represented; entities consider themselves social institutions (85\% of organizations) rather than SEs or firms (38\% and $40 \%$ of organizations respectively).

\subsubsection{Cluster 2}

The 99 organizations included in Cluster 2 exclusively serve the jobless, i. e. unemployment insurance beneficiaries and social assistance recipients.

27 «Workplaces with occupational purpose» refer to individual and/or group activities aimed at promoting the development of personal and social skills and enabling the beneficiary's selfactualization (DSS 2005).

28 «Workplaces in production and sales» are focused on promotion, conservation and/or acquisition of skills, behaviors and motivations suitable for a working environment and should simultaneously allow beneficiaries to exercise a paid job in a sheltered context (DSS 2005). 
The most common legal forms are not-for-profit (68\% of organizations), but companies (18\%) and the public sector (14\%) are also represented. Compared with Cluster 1, a significant number of organizations are younger and smaller. They generate average annual costs of around 3.5 million SFr and reach an annual average of 73 beneficiaries. The average level of sales turnover is relatively high if compared to costs and amounts to 812,000 SFr. Service provision for the disadvantaged workers is focused on workplaces in production and sales (83\% of organizations), consulting, coaching and job placement activities $(82 \%)$, in addition to providing workplaces with an occupational purpose (75\%). Self-perception is less in this second cluster compared with the first cluster: $57 \%$ of the organizations consider themselves social enterprises; the corresponding value for social institutions or companies is $51 \%$ each. Based on these results, Cluster 2 shows the highest share of organizations that perceive themselves as SE.

\subsubsection{Cluster 3}

Most of the 41 organizations of Cluster 3 (66\%) work with mixed target groups, i. e. with both the disabled and the jobless; the remaining $34 \%$ only work with the disabled. With regard to the legal form, a certain level of heterogeneity can be observed: $51 \%$ of organizations are companies, $30 \%$ belong to the public sector and the remaining 20\% adopt legal forms that are typical of the not-for-profit sector. A certain degree of heterogeneity also exists with respect to the year of establishment: $46 \%$ of organizations were set up before 1990 but a further $34 \%$ were founded between 1990 and 2000. This cluster is mainly composed of medium-sized WISEs with average annual costs of approximately 6.5 million SFr and an annual number of beneficiaries averaging 146. Of particular interest here is the fact that up to $31 \%$ of organizations indicate that their most important source of funding is market sales revenues (the annual average turnover in the whole cluster is 2.3 million SFr). The market reliance is thus the highest among these SEs. The service provision focuses on workplaces in production and sales (71\% of organizations), consulting, coaching and job placement activities, as well as vocational training (68\% each). Like Cluster 2, the self-perception is rather heterogeneous: most organizations consider themselves to be a social institution (78\%); a company (51\%), those that view themselves as a SE (49\%) are less common. In contrast to what could be observed in the other clusters, a positive and significant correlation exists between the perception of oneself as a company and the perception of oneself as a SE. This means that the more an organization sees itself as a company, the more likely it is to consider itself as a SE too. 


\subsubsection{Cluster 4}

Like in Cluster 3, the 113 organizations belonging to Cluster 4 only work with mixed target groups. This cluster includes organizations that use a traditional not-for-profit legal form; most of them (74\%) were established before 1990. The annual costs amount to approximately 9.5 million SFr on average and the number of supervised beneficiaries averages 125 annually (thus reflecting how large the organizations in this cluster are). The amount of sales turnover is quite high as well (2.3 million SFr on average), however market based revenue only accounts as a main source of funding for $15 \%$ of these. The service range is wide and corresponds to that of WISEs in Cluster 2, with workplaces in production and sales (89\% of entities), consulting, coaching and job placement activities (82\%), as well as vocational training (80\%). Furthermore, a significant proportion of the cluster also offer educational services (64\% of organizations). In relation to the subjective identity, $66 \%$ of WISEs consider themselves as social institutions, $61 \%$ as companies and $51 \%$ as SEs.

\section{Future Challenges}

The Swiss SE sector is pretty young. Its visibility, and recognition for the sector, is still ambiguous and the debates surrounding its usefulness and legitimacy are sometimes heated. The "WISE model" has certainly the potential of being an innovative and effective player in fighting against poverty and social exclusion. However, WISEs currently need to face several issues and challenges in order to be able to reach their economic and social goals. The most significant of these challenges are now outlined.

A first tension is linked to the double bottom line of SEs (i. e. both financial and social performance). SEs are neither classical not-for-profit organizations nor fully accepted players in the market. This puts them in a double-bind situation: on the one side they are treated as classical NPOs that have to fulfill strict accountability rules and are often not allowed to capitalize any profit because of the public subsidies they receive. ${ }^{29}$ On the other side, they have a market

29 In this regard, the recent shift towards New Public Management principles and the spread in many Cantons of service agreements between public bodies and SEs (usually including a socalled "global budget") implies both advantages and drawbacks. On the one side, it entails the opportunity to at least partially capitalize the financial surplus, and is an incentive towards more economic efficiency. On the other side, quality management and outputs monitoring are often complex and time-consuming activities; moreover, there is a risk of an excessive 
orientation and need to compete with other commercial actors, in order to guarantee their economic viability. This tension increases the risk of a mission shift, i. e. an isomorphism process towards traditional NPOs or towards for-profit companies. While it could also entail a risk to stifle the richness of the initiatives and to overshadow the types that do not enjoy formal recognition, the adoption of specific legal forms for SEs could help in formally acknowledging and recognizing their double bottom-line and fostering the development of the sector. Indeed, as suggested by Fici (2015), a specific legal identity for SE could allow for the design of specific public policies in favour of social enterprises; to protect their various stakeholders, to prevent the creation and operation of "false" SEs and to establish clearer boundaries between social enterprise and other concepts, such as corporate social responsibility and the secondary labour market. The experiences of other European countries show that legislation designed for SE has succeeded when the SE community has been involved in the drafting process and when new laws have managed to seize an already existing process of bottom-up creation of SE initiatives (Borzaga and Galera 2016).

A related issue concerns the positioning that WISEs should have in the market of goods and services. One often argues that a SE should be active in noncompetitive markets, in order to avoid the potential loss of regular jobs. Whereas the discovery of new products and sectors (or the recovering of old ones) is not bad in itself and reduces this "competition threat", niches and social utility sectors are often not very profitable. Moreover, it makes it more difficult to provide the beneficiaries with the technical skills that are required in the mainstream labour market. This could indeed be a limit if the strategy consists of creating an "intermediate economy" (Defourny, Favreau, and Laville 1998) and integrating the target group in conventional jobs. As suggested by Dunand and Rey (2013), the problem could be regulated by the various stakeholders at the local level, through the shared definition of limited market shares accessible for WISEs. On the other hand, if the overarching goal is the long term integration within a SE, the strategy of developing a "complementary" or a "social utility" sector seems more favourable. While it offers more stable workplaces, this option entails some risks of exclusion as well. The latter could be related in particular to the marginal position in the labour market and the lack of income improvement opportunities (Hansen et al. 2002). ${ }^{30}$

standardization of the services provided by SEs and an incentive to "stick" to the outputs parameters defined in the agreements.

30 Nevertheless, given the heterogeneity of the target groups and the complexity of the challenges, it seems crucial to recognize the usefulness of maintaining differentiated approaches in fighting against social exclusion (cfr. Defourny, Favreau, and Laville 1998). 
A further challenge is linked to the institutional trajectories of WISEs, which have historically emerged within three distinct social security regimes: invalidity insurance, unemployment insurance and social assistance. Although the different "families" of WISEs tend to mix with each other to some extent (mixed target groups and mixed sources of funding), contract forms, remuneration models and integration goals for the disadvantaged employees still depend much on their administrative category and not necessarily on their capacities and needs. The current challenge for SEs is to gain a sufficient degree of autonomy and overcome the administrative logics, in order to better respond to the specific needs of the beneficiaries. It seems particularly important to develop initiatives which provide social assistance recipients with long-term job opportunities, since that target group is currently facing growing integration needs. To avoid a "workfare drift", the participant's capability of voice and choice should be safeguarded, and the WISE should be able to offer a "fair" status and a market salary to their disadvantaged employees. The latter must not necessarily be self-financed by the SE: a temporary or permanent co-financing by the public bodies seems justified if the workers cannot reach a sufficient degree of performance.

A strategy to gain a higher autonomy from public policies and the capability of creating additional jobs for the target group include the achievement of a stronger financial independence of the market activity. In this regard, we see at least two possible developments.

Firstly, whereas it seems appropriate that public bodies subsidize the integration services provided by SEs, the commercial activity should be mainly supported through public contracts for the provision of goods and services (contracting out), as already happens in other European countries. In this regard, public procurement rules should allow for reserved contracts for SEs and social clauses in favour of organizations offering goods and services with a sufficiently high level of positive social impacts (Borzaga and Galera 2016).

A second favourable development would be an extension of the SE models, currently almost limited to the entrepreneurial not-for-profit type, in order to include other SE "matrices", such as the social cooperative and the social business (Defourny and Nyssens 2016). A promising way forward consists of establishing favourite relationships between third-sector initiatives and SMEs with a strong territorial attachment but facing growing difficulties to maintain their competitiveness. This "contamination" is likely to better ensure both the achievement of the social goal and the financial sustainability of the projects.

However, if Swiss SEs decide to become more involved in the provision of community services or to give up their privileged relationship with the public sector, this will require, in our opinion, more democratic and multi-stakeholder 
decision-making processes in order to ensure the pursuit of a plurality of (economic, social and socio-political) objectives and interests.

Finally, there is still little scientific evidence supporting the "narrative" regarding WISEs' as a powerful player for poverty reduction. ${ }^{31}$ This appears to be a crucial issue for the recognition of the usefulness of these initiatives. Therefore, one of the major contributions of academia in the near future would be addressing the measurement of the economic and social impacts of SEs, as well as identification of their success factors.

\section{References}

Adam, S. M., J. Amstutz, G. Avilés, E. Cavedon, L. Crivelli, D. Ferrari, A. Gafner, S. Greppi, A. Lucchini, D. Pozzi, et al. 2016. Explorative Studie zu den Erfolgsfaktoren der Unternehmen der sozialen und beruflichen Integration. Beiträge zur sozialen Sicherheit, Nationales Programm zur Prävention und Bekämpfung von Armut, Forschungsbericht Nr. 4/16. Bern: Bundesamt für Sozialversicherungen.

Adam, S. M. 2013. “Artikel 'Sozialfirma'.” In Lexikon Der Sozialwirtschaft, edited by B. Maelicke. Baden-Baden: Nomos Verlag.

Adam, S. M. 2012. Die Sozialfirma - wirtschaftlich arbeiten und sozial handeln, 2nd printing. Bern: Haupt Verlag.

Adam, S. M. 2008. Die Sozialfirma - wirtschaftlich arbeiten und sozial handeln. Berne: Haupt Verlag.

Amgarten, R., and R. Widmer. 2007. Die Sozialfirmen in der Schweiz. Eine Untersuchung ausgewählter Parameter zur Definition dieser Unternehmen. Luzern: Hochschule für Soziale Arbeit.

Bertozzi, F., G. Bonoli, and F. Ross. 2008. "The Swiss Road to Activation: Legal Aspects, Implementation and Outcomes." In Bringing the Jobless into Work? Experiences with Activation Schemes in Europe and the US, edited by W. Eichhorst, O. Kaufmann, and R. Konle-Seidl, 121-59. Berlin: Springer.

Borzaga, C., and G. Galera. 2016. Social Enterprises and Their Eco-Systems: Developments in Europe. Luxembourg (Publications Office of the European Union): European Commission, Directorate-General for Employment, Social Affairs and Inclusion.

BSV. 2014. Geschichte Der Sozialen Sicherheit in Der Schweiz. Berne: Bundesamt für Sozialversicherungen. http://www.geschichtedersozialensicherheit.ch/home.

Campi, S., J. Defourny, and O. Grégoire. 2006. "Work Integration Social Enterprises: Are They Multiple-Goal and Multi-Stakeholder Organizations?" In Social Enterprise. At the Crossroads of Market, Public Policies and Civil Society, edited by M. Nyssens, 29-49. London and New York: Routledge.

31 This is true not only in the Swiss context, but probably also at the international level. Indeed, among 447 research projects funded by the EU during the period 1994-2013, none dealt directly with the role WISEs have in poverty prevention and reduction (Harkiolakis, Prinia, and Mourad 2012). 
Crivelli, L., A. Bracci, and G. Avilés. 2012a. The Swiss social enterprise model - Results of a nationwide exploratory survey, Project report, SNF-DORE, Nr. 117954. http://www.bsv.admin.ch/themen/gesellschaft/00074/03195/index.html?lang=en.

Crivelli, L., A. Bracci, and G. Avilés. 2012b. Il modello d'impresa sociale "made in Switzerland". Risultati di un'indagine esplorativa condotta su piano nazionale, Euricse WP 38/12. http://www.euricse.eu/it/node/2168.

Da Cunha, A., M. Buchs, and F. Rivola. 2014. Les entreprises sociales d'insertion en Valais: vers une économie inclusive? Quatre études de cas. Lausanne: Cahiers de Recherche Urbaine, Université de Lausanne.

Darioli, S. 2013. Créer des entreprises sociales: perspectives, limites et...risques, Dossier du mois de l'Artias, mars 2013.

Davister, C., J. Defourny, and O. Grégoire. 2003. Les entreprises sociales d'insertion dans l'Union Européenne: un aperçu général, EMES WP 03/11.

De Jonckheere, C., S. Mezzena, and C. Molnarfi. 2008. Les entreprises sociales d'insertion par l'économique. des politiques, des pratiques, des personnes et des paradoxes. Geneva: IES éd.

Defourny, J., L. Favreau, and J. -L. Laville. 1998. “Pistes d'avenir dans une économie plurielle.” In Insertion et nouvelle économie sociale. Un bilan international, J. Defourny, L. Favreau and J. -L. Laville (sous la direction), 339-63. Paris: Desclée de Brouwer.

Defourny, J., and M. Nyssens. 2012. "Les conceptualisations internationales de l'entreprise sociale." In Entreprise sociale et insertion. Une perspective internationale, edited by L. Gardin, J. -L. Laville and M. Nyssens, 13-35. Paris: Desclée de Brouwer.

Defourny, J., and M. Nyssens. 2016. "Fundamentals for an International Typology of Social Enterprise Models." ICSEM Working Papers, No. 33, Liege: The International Comparative Social Enterprise Models (ICSEM) Project.

DSS. 2005. Catalogo dei servizi e delle prestazioni. Bellinzona: Dipartimento della sanità e della socialità del Canton Ticino, Divisione dell'azione sociale e delle famiglie.

Dunand, C., and A. -L. Du Pasquier. 2006. Travailler pour s'insérer. Des réponses actives face au chômage et à l'exclusion: les entreprises de réinsertion. Geneva: ies éditions.

Dunand, C. 2012. "Les entreprises sociales d'insertion par l'économique en suisse." In Entreprise sociale et insertion. Une perspective international, edited by L. Gardin, J. -L. Laville, and M. Nyssens, 247-73. Paris: Desclée de Brouwer.

Dunand, C., and J. -C. Rey. 2013. Synthèse du 2ème colloque national sur les entreprises sociales d'insertion par l'économique (ESIE) du 6 novembre 2012 à Sierre, Actes du colloque.

Ferrari, D., S. M. Adam, J. Amstutz, G. Avilés, L. Crivelli, S. Greppi, A. Lucchini, D. Pozzi, D. Schmitz, B. Wüthrich, et al. 2016. Sozialfirmen in der Schweiz. Grundlagen zur Beantwortung des Postulats Carobbio Guscetti «Rolle der Sozialfirmen» (13.3079). Forschungsbericht Nr. 9/16. Bern: Bundesamt für Sozialversicherungen.

Fici, A. 2015. "Recognition and Legal Forms of Social Enterprise in Europe: A Critical Analysis from a Comparative Law Perspective”. Euricse Working Paper Series 82 (15).

Gonin, M., and N. Gachet. 2015. Social Enterprise in Switzerland: An Overview of Existing Streams, Practices and Institutional Structures. ICSEM Working Papers, No. 3. Liege: The International Comparative Social Enterprise Models Project (ICSEM).

Hansen, H., P. Hespanha, C. Machado, and R. van Berkel. 2002. “Inclusion Through Participation? Active Social Policies in the EU and Empirical Observations from Case Studies Into Types of Work." In Active Social Policies in the EU. Inclusion Through 
Participation? edited by R. van Berkel and I. Moller Hornemann, 103-35. Bristol: The Policy Press.

Harkiolakis, N., D. Prinia, and L. Mourad. 2012. "Research Initiatives of the European Union in the Areas of Sustainability, Entrepreneurship, and Poverty Alleviation." Thunderbird International Business Review 54 (1):73-8.

Hulgard, L., and R. Spear. 2006. "Social Entrepreneurship and the Mobilization of Social Capital in European Social Enterprises." In Social Enterprise. At the Crossroads of Market, Public Policies and Civil Society, edited by M. Nyssens, 85-108. London and New York: Routledge.

Kehrli, C. 2007. Entreprises sociales en Suisse. Caractéristiques, Intérêt, Questions. Lucerne: Editions Caritas.

Lindenmeyer, H., and K. Walker. 2010. Arbeitslosenversicherung und Sozialhilfe: Zusammenarbeit bei der Arbeitsvermittlung. Studie zur Zusammenarbeit RAV-Sozialhilfe, Studie im Auftrag der Direktion für Arbeit des SECO, SECO Publikation Arbeitsmarktpolitik N. 31.

Marée, M. 2005. Les impacts collectifs de l'insertion - Définition, typologie et techniques de mesure, Rapport rédigé dans le cadre du contrat de recherche "Economie sociale, intégration sociale et développement durable” de la Politique scientifique fédérale, Université de Liège.

Pfister, N. 2009. Integrationsauftrag der Sozialhilfe in der Praxis. Eine Standortbestimmung der SKOS basierend auf einer Befragung von 20 Sozialdiensten, SKOS.

Tattini, V., and M. D. Bruttin. 2006. Entreprises sociales d'insertion en Suisse: une première approche, L'Alliance de recherche universités-communautés en économie sociale, Québec. VPOD. 2007. Positionspapier zur Auseinandersetzung um Teillohnjobs, Existenzsicherung und Erwerbsarbeit. Zürich: VPOD.

Wüthrich, B., J. Amstutz, and S. M. Adam. 2012. "Sozialfirmen und ihr Beitrag zur beruflichen Integration von Menschen mit Beeinträchtigungen. Eine explorative Annäherung an ein innovatives Modell." In Die Sozialfirma - wirtschaftlich arbeiten und sozial handeln, edited by S. M. Adam. Bern: Haupt Verlag. 